\title{
Cyclooxygenase-2 in tumor-associated macrophages promotes breast cancer cell survival by triggering a positive-feedback loop between macrophages and cancer cells
}

\author{
Hongzhong Li ${ }^{1}$, Bing Yang ${ }^{1}$, Jing Huang ${ }^{1}$, Yong Lin ${ }^{1}$, Tingxiu Xiang ${ }^{1}$, Jingyuan Wan ${ }^{2}$, \\ Hongyuan Li ${ }^{1}$, Salem Chouaib ${ }^{3}$, Guosheng Ren ${ }^{1}$ \\ ${ }^{1}$ Chongqing Key Laboratory of Molecular Oncology and Epigenetics, The First Affiliated Hospital of Chongqing Medical \\ University, Chongqing, China \\ ${ }^{2}$ Department of Pharmacology, Chongqing Medical University, Chongqing, China \\ ${ }^{3}$ Unite INSERM U753, Institut de Cancerologie Gustave Roussy, Paris, France \\ Correspondence to: \\ Guosheng Ren, e-mail: rengs726@126.com
}

Keywords: tumor microenvironment, macrophages, breast cancer, cyclooxygenase-2, prostaglandin $E_{2}$

Received: May 13, 2015

Accepted: July 28, 2015

Published: August 10, 2015

\section{ABSTRACT}

Tumor-associated macrophages (TAMs) play an important role in cancer cell survival, however, the mechanism of which remains elusive. In this study, we found that COX-2 was abundantly expressed in breast TAMs, which was correlated to poor prognosis in breast cancer patients. Ectopic over-expression of COX-2 in TAMs enhanced breast cancer cell survival both in vitro and in vivo. COX-2 in TAMs was determined to be essential for the induction and maintenance of M2-phenotype macrophage polarity. COX-2+ TAMs promoted breast cancer cell proliferation and survival by increasing $\mathrm{Bcl}-2$ and $\mathrm{P}-\mathrm{gp}$ and decreasing Bax in cancer cells. Furthermore, COX-2 in TAMs induced the expression of COX-2 in breast cancer cells, which in turn promoted M2 macrophage polarization. Inhibiting PI3K/Akt pathway in cancer cells suppressed COX-2+ TAMs-induced cancer cell survival. These findings suggest that COX-2, functions as a key cancer promoting factor by triggering a positive-feedback loop between macrophages and cancer cells, which could be exploited for breast cancer prevention and therapy.

\section{INTRODUCTION}

The tumor microenvironment comprises a variety of stromal cells that play an essential role in tumor initiation and progression [1]. Tumor associated macrophages (TAMs), the most abundant inflammatory stromal cells in malignant tumors including breast cancer, have been implicated in orchestration of many stages of tumor progression such as tumor growth, angiogenesis, metastasis, and resistance to treatment, through releasing various factors including chemokines, inflammatory and growth factors $[2,3]$. Several studies have indicated that increased infiltration of TAMs to breast cancer is strongly associated with poor prognosis in patients $[4,5]$.

Macrophages have a tremendous plasticity and can change their functional profiles repeatedly in response to environmental stimuli. When exposed to lipopolysaccharides (LPS) and IFN- $\gamma$, macrophages are polarized to proinflammatory M1 (classical) macrophages and exert strong microbicidal and tumoricidal activities. Conversely, when exposed to Th2 cytokines such as IL-4 and IL-13, they are polarized to immunosuppressive M2 macrophages and involved in parasite containment, tissue remodeling and tumor progression. Compared with M1 macrophages, M2 macrophages do not produce proinflammatory mediators such as tumor necrosis factor- $\alpha$ (TNF- $\alpha$ ), IL-1 $\beta$ and IL-12/23, but express high levels of immunosuppressive cytokines such as IL-10 and TGF- $\beta$, high arginase-1 activity and specific surface markers such as CD163 and CD206 (mannose receptor). Functional plasticity of macrophages during tumor progression has been proposed. Macrophages at early stages of tumor initiation show an M1 phenotype, while TAMs in established tumors show an M2-biased phenotype. As a 
particular pathophysiological consequence in the setting of cancer, the M1-M2 switch is the key step that accelerates tumor aggressiveness $[2,6,7]$.

A large body of work describing a link between inflammation and cancer has generated intense interest in Cyclooxygenase-2 (COX-2) that is the rate-limiting enzyme in the metabolic conversion of arachidonic acid (AA) into various prostaglandins (PGs) including prostaglandin $\mathrm{E}_{2}\left(\mathrm{PGE}_{2}\right)$ for mediating inflammation and cancer progression. Over-expression of COX-2 has been detected in a number of malignancies including breast cancer, and contributes to carcinogenesis by stimulating cancer cell proliferation, inhibiting apoptosis, increasing invasiveness and modulating inflammation and immunity $[8,9]$. Clinical studies have noted a reduced risk for breast, lung, prostate, and colon cancers after treatment with non-selectively COX-2 inhibition by non-steroidal anti-inflammatory drugs (NSAIDs) or selective COX-2 inhibition with COX-2 inhibitors $[10,11]$. COX-2 and its products, particularly $\mathrm{PGE}_{2}$, act via classical cancer signaling pathways in primary tumor cells to promote tumorigenesis. Recent evidence has shed a spotlight not only on the tumor cell itself, but also the tumor microenvironment, especially macrophages in the tumor [12]. COX-2-positive TAMs are found in more advanced melanoma, and appear to act as a biomarker for melanoma progression [13]. TAMs in the post-irradiated tumor microenvironment express a higher level of COX-2, and promote early prostate cancer growth in mice [14]. Although these data suggest that COX-2 in TAMs might participate in cancer process, its exact role and mechanism of which has not been well elucidated. In this study, we aim to investigate the contribution of COX-2 in TAMs to breast cancer progression, and to explore the mechanisms underlying the process.

\section{RESULTS}

\section{High COX-2 expression in TAMs in breast cancer}

Primary TAMs isolated from breast cancer tissue produced a large amount of IL-10 and arginase-1, and a small amount of IL-12/23, and exhibited a cluster of differentiation (CD) $163^{\text {high }} / C D 206^{\text {high }}$ phenotype (Supplementary Figure S1). MDMs-derived TAMs established by in vitro co-culture of normal macrophages (monocyte-derived macrophages, MDMs) with breast caner cells for 7 days, also showed more M2-like characteristics than untreated MDMs (Supplementary Figure S1). Real-time PCR was performed to measure COX-2 expression in TAMs isolated from breast cancer patients, paired peripheral blood monocytes (PBMs), normal MDMs and MDMs-derived TAMs. The mRNA expression of COX-2 was significantly higher in primary TAMs and MDMs-derived TAMs, compared with that in PBMs and untreated MDMs (Figure 1A). Furthermore, MDMs-derived TAMs produced abundant amounts of $\mathrm{PGE}_{2}$ in the supernatants (Figure 1B). These results suggested that there was increased COX-2 expression and function in breast cancer TAMs.
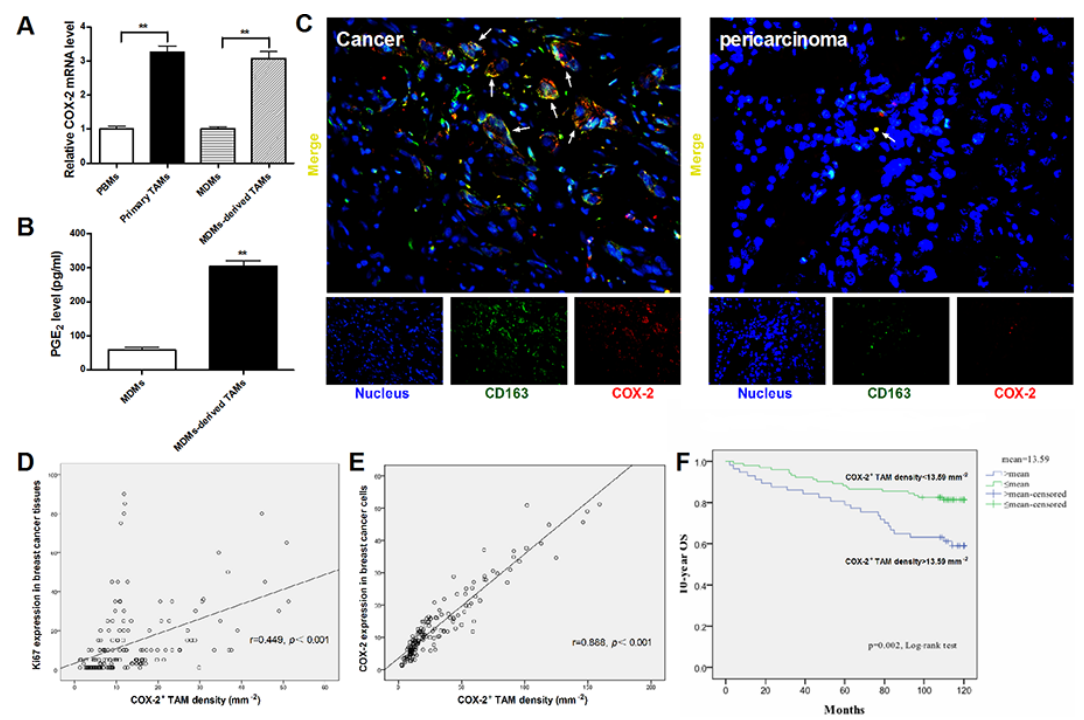

Figure 1: High COX-2 expression in breast cancer TAMs. A. The relative COX-2 mRNA expression in different monocytes/ macrophages. Mean $\pm \mathrm{SD}, n=9, * * p<0.01$. B. PGE 2 amount in supernatants of MDMs or MDMs-derived TAMs was measured by CIA assay. Mean $\pm \mathrm{SD}, n=9, * * p<0.01$. C. The representative double immunofluorescence staining of CD163 (green) and COX-2 (red) in breast cancer tissues (Left) or pericarcinoma tissues (Right) (original magnification, $\times 400$ ). D. Correlation of COX $-2^{+}$TAMs and Ki67 in breast cancer tissues $(n=160)$ was analyzed by Pearson's correlation analysis. E. Correlation of COX-2 TAMs and COX-2 in breast cancer cells $(n=160)$ was analyzed by Pearson's correlation analysis. F. Kaplan-Meier 10-years OS curves for breast cancer patients according to COX-2 ${ }^{+}$TAMs density $(n=160)$. 


\section{High COX-2 expression in TAMs correlates with poor prognosis in breast cancer patients}

In order to determine the role of COX-2 in breast TAMs, a double immunofluorescent staining of COX-2 and CD163 (a specific marker for TAMs) was performed in a breast tissue array containing 160 human breast cancer tissue specimens and 10 pericarcinoma tissue controls. A greater number of $\mathrm{COX}-2^{+}$macrophages were found in cancer samples than that in nonmalignant pericarcinoma samples $(p<0.001$, Figure 1C). The number of COX-2+ TAMs was associated with increased clinical staging $(p=0.024)$ and aggressive tumor biology by advanced histopathological grading $(p<0.001)$ and lymph node metastasis $(p=0.021)$ (Table 1$)$. Furthermore, there was a significant positive correlation between
COX $-2^{+}$TAMs and the cell proliferation marker Ki67 $(r=0.449, p<0.001$, Figure 1D) or COX-2 expression $(r=0.888, p<0.001$, Figure 1E) in breast cancer cells. However, there was no association between $\mathrm{COX}-2^{+} \mathrm{TAM}$ counts and other clinical parameters including patient age and molecular subtypes $(p>0.05)$. Kaplan-Meier survival curve with a median follow-up period of 118 months demonstrated that a significantly higher overall survival (OS) rate was observed in patients with low $\mathrm{COX}-2^{+}$ TAM counts than those with high COX-2 ${ }^{+}$TAM counts $(p<0.01$, Figure 1F). In a multivariate Cox regression analysis, COX-2 $2^{+}$TAM counts were associated with poor survival prognosis of breast cancer patients $(\mathrm{HR}=2.085$, $p=0.036$ ), independent of other clinical covariates (Table 2), indicating that COX-2+ TAM is an independent prognostic biomarker for breast cancer outcome, and

Table 1: Correlation of COX-2 Expressing TAM Counts with Clinicopathological Status in 160 Cases of Patients with Breast Cancer

\begin{tabular}{|c|c|c|c|}
\hline Clinicopathological Status & COX2 $2^{+}$TAMs $\left(>13.59 \mathrm{~mm}^{-2}, n=57\right)$ & COX2 $2^{+}$TAMs $\left(\leq 13.59 \mathrm{~mm}^{-2}, n=103\right)$ & $p$ Value \\
\hline Age (years) & $52 \pm 14.68$ & $54.50 \pm 12.24$ & 0.252 \\
\hline Tumor size $\left(\mathrm{mm}^{3}\right)$ & $60.16 \pm 216.32$ & $24.59 \pm 44.34$ & 0.225 \\
\hline TNM Stage & & & $<0.001$ \\
\hline I & $5(8.77 \%)$ & $12(11.65 \%)$ & \\
\hline II & $20(35.09 \%)$ & $76(73.79 \%)$ & \\
\hline III & $32(56.14 \%)$ & $15(14.56 \%)$ & \\
\hline Histological Grade & & & 0.024 \\
\hline I & $10(17.55 \%)$ & $34(33.01 \%)$ & \\
\hline II & $42(73.68 \%)$ & $68(66.02 \%)$ & \\
\hline III & $5(8.77 \%)$ & $1(0.97 \%)$ & \\
\hline Metastasis & & & 0.021 \\
\hline Yes & $46(80.70 \%)$ & $47(45.63 \%)$ & \\
\hline No & $11(19.30 \%)$ & $56(54.37 \%)$ & \\
\hline ER & & & 0.527 \\
\hline+ & $42(73.68 \%)$ & $71(68.93 \%)$ & \\
\hline- & $15(26.32 \%)$ & $32(31.07 \%)$ & \\
\hline PR & & & 0.479 \\
\hline+ & $37(64.91 \%)$ & $61(59.22 \%)$ & \\
\hline- & $20(35.09 \%)$ & $42(40.78 \%)$ & \\
\hline HER2 & & & 0.067 \\
\hline+ & $14(24.56 \%)$ & $40(38.83 \%)$ & \\
\hline- & $43(75.44 \%)$ & $63(61.17 \%)$ & \\
\hline Ki67 & & & 0.03 \\
\hline$+(\leq 5 \%)$ & $34(59.65 \%)$ & $43(41.75 \%)$ & \\
\hline$-(>5 \%)$ & $23(40.35 \%)$ & $60(58.25 \%)$ & \\
\hline
\end{tabular}


Table 2: Multivariate Cox regression analysis of potential prognostic factors for breast cancer

\begin{tabular}{|l|c|c|c|}
\hline \multicolumn{1}{|c}{ clinical characteristics } & Hazard ratio & 95\% CI & P values \\
\hline Age, $y>60$ & 1.694 & $0.902-3.181$ & 0.101 \\
\hline Tumor size $(>2 \mathrm{~cm})$ & 0.648 & $0.314-1.337$ & 0.240 \\
\hline TNM stage $(\mathrm{III})$ & 2.015 & $1.032-3.933$ & 0.040 \\
\hline Histological Grade (>II) & 2.925 & $1.096-7.802$ & 0.032 \\
\hline ER & 0.798 & $0.418-1.532$ & 0.494 \\
\hline PR & 0.691 & $0.369-1.295$ & 0.249 \\
\hline HER2 & 1.795 & $0.939-3.433$ & 0.077 \\
\hline Ki67 & 0.902 & $0.488-1.668$ & 0.743 \\
\hline Density of COX-2 ${ }^{+}$TAM $\left(>13.59 \mathrm{~mm}^{-2}\right)$ & 2.085 & $1.050-4.140$ & 0.036 \\
\hline
\end{tabular}

COX-2 in TAMs may play an important role in breast cancer progression.

\section{Over-expression of COX-2 in TAMs promotes breast cancer cell proliferation and survival}

In order to elucidate the tumor-promoting role of COX-2 in breast TAMs, TAMs were first transfected with adenoviral COX-2 or siRNA COX-2 (Supplementary Figure S2), and then co-cultured with different breast cancer cell lines (MCF-7 and MDA-MB-231) for 7 days. Cancer cell proliferation, viability or apoptosis induced by various cytotoxic drugs were measured by CCK-8 or PI staining assays, respectively. We found that TAMs promoted proliferation and resistance to drugs-induced apoptosis in breast cancer cells, which was enhanced by COX-2 overexpression but attenuated by COX-2 knockdown in TAMs (Figure 2A-2B and Supplementary Figure S3). Consistent with these in vitro findings, higher mammary tumor weight/ volume was observed in NOD/SCID mice injected with 4T1 murine breast cancer cells/RAW 264.7-derived TAMs, compared with that in mice injected with 4T1 cells only. Tumor weight/volume was much higher in mice injected with $4 \mathrm{~T} 1 / \mathrm{COX}-2^{+}$TAMs, while lower in mice injected with 4T1/COX-2- TAMs than that in mice injected with 4T1/normal TAMs (Figure 2C). Furthermore, significantly increased proliferation (Ki- 67 staining) and decreased apoptosis (cleaved caspase 3 staining) were detected in the tumor specimens of mice injected with $4 \mathrm{~T} 1 / \mathrm{COX}-2^{+}$ TAMs, while an inverse result was obtained from mice injected with 4T1/COX-2- TAMs, compared with that of mice injected with 4T1/normal TAMs (Figure 2D-2E).

\section{$\mathrm{PGE}_{2}$ is unlikely the only mediator of the effect of TAMs COX-2 on breast cancer cells}

As the key factor for the biological function of the COX-2 pathway, $\mathrm{PGE}_{2}$ activates intracellular signal transduction by binding to the E-series of prostaglandin receptors EP1, EP2, EP3 and EP4. Increasing studies indicate that EP2 and EP4 are the main EP subtypes involved in mammary tumor progression [15]. In order to investigate whether COX-2 in macrophages exerted pro-tumor activity mainly through direct $\mathrm{PGE}_{2}$ effect on cancer cells, the expression of EP2 and EP4 in breast cancer cells was confirmed (Figure 3A). The antagonist against EP2 (AH6809) and EP4 (AH23848) were used to block the $\mathrm{PGE}_{2}$ signaling. The results showed that inhibiting the $\mathrm{PGE}_{2}$ signal pathway only partly attenuated cell proliferation and drug resistance in breast cancer cells induced by TAMs (Figure 3B-3C), suggesting that other mediators are involved in COX-2-mediated communication between TAMs and breast cancer cells.

\section{COX-2 is essential for macrophages polarized to M2 phenotype}

Since the polarization of infiltrating macrophages to M2-like TAMs is the key step that promotes tumor development by inducing various tumor-related cytokines, we next investigated whether COX-2 in TAMs promoted cancer cell survival and proliferation by enhancing macrophages polarity. The expression of EP1-4 in MDMs and TAMs was confirmed (Supplementary Figure S4). The phenotypes of macrophages transfected with adenoviral COX-2 or siRNA COX-2 were then identified by detection of arginase activity and cytokines. We found that COX-2 over-expression or exogenous $\mathrm{PGE}_{2}$ promoted MDMs polarized to M2 phenotype. In contrast, TAMs treated with siRNA COX-2 lost M2 phenotype (Figure 3D-3G). These results sytrongly suggest that COX-2 is an essential factor for the induction and maintenance of M2 polarity in TAMs.

\section{COX-2 in TAMs increases the expression of Bcl-2 and P-glycoprotein and decreases Bax expression in breast cancer cells}

Apoptosis is a well-orchestrated process regulated by multiple pro-apoptotic and anti-apoptotic factors, particularly the Bcl-2 family members. These factors 

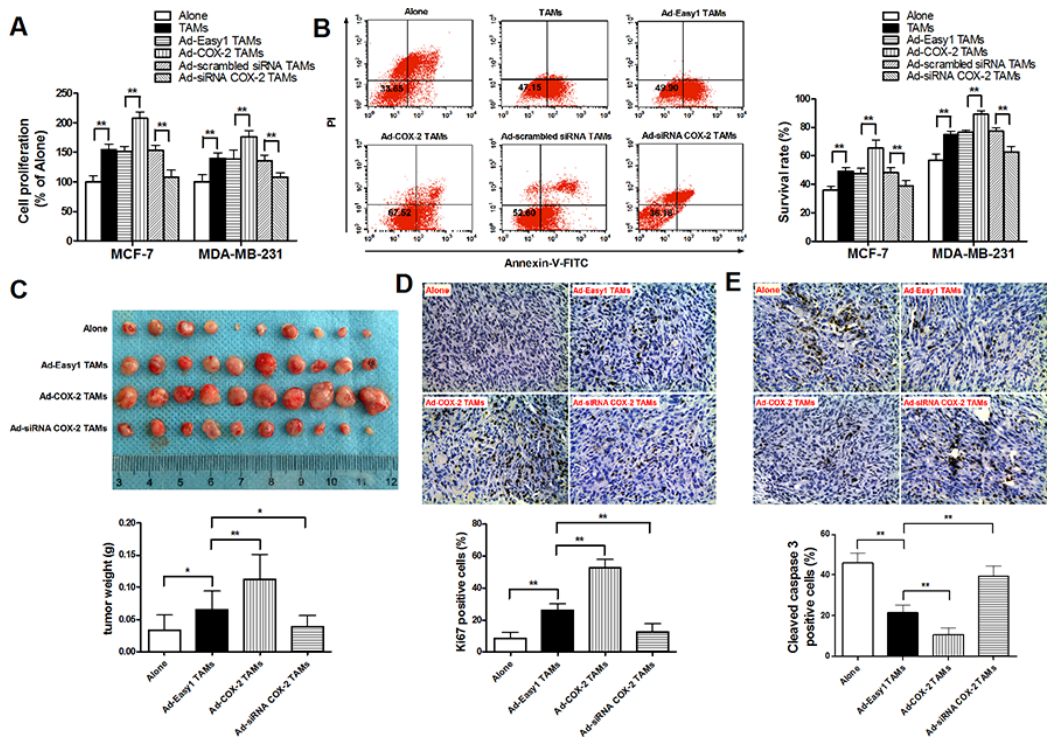

Figure 2: COX-2 in macrophages promotes breast cancer growth. A. Cell proliferation assay. After breast cancer cells were co-cultured with or without TAMs transfected with adenoviral COX-2 or siRNA COX-2 for 7 days, cell proliferation was measured by CCK-8 kit. Data were expressed as a ratio of treated cells to control (Alone) cells. B. Cell apoptosis in breast cancer cells induced by adriamycin (ADM) was examined by flow cytometry analysis of Annexin V-FITC/PI staining. Numbers inside dot plots indicate the percentages of survival cells. C. 4T1 cells alone or with Raw264.7-derived TAMs transfected with adenoviral COX-2 or siRNA COX-2 were injected into the mammary fat pads of NOD/SCID mice. Tumor weight was measured in different groups. D. and E. Ki-67 staining for cell proliferation and cleaved caspase 3 for apoptosis were evaluated by IHC (original magnification, $\times 400$ ). The number of stained and unstained cells was counted to generate the percentage of positive cells in each group. All the data were presented as the mean $\pm \mathrm{SD}$, $n=10,{ }^{*} p<0.05$ and $* * p<0.01$.

A

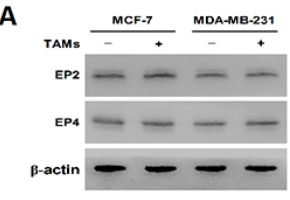

B

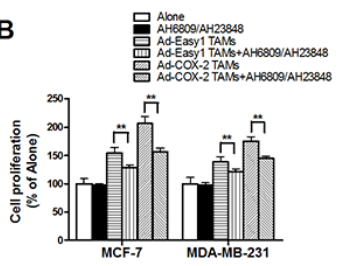

C

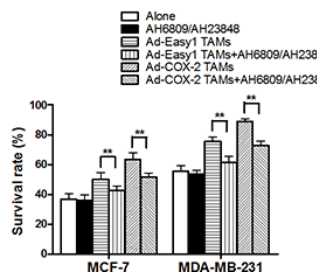

D
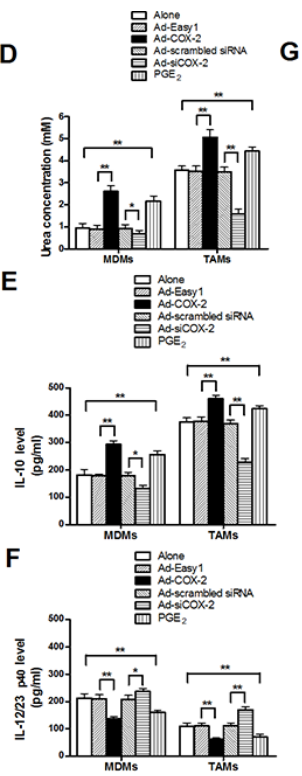

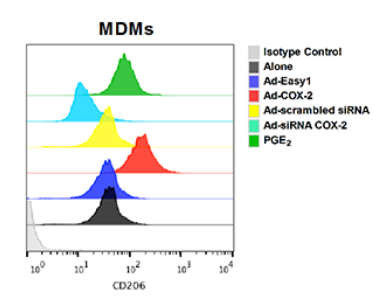

TAMs

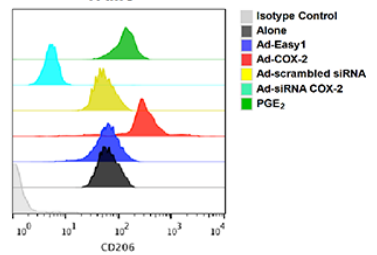

Figure 3: COX-2 is essential for macrophages polarized to M2 phenotype. A. The expression of EP2 and EP4 in breast cancer cells co-cultured with or without TAMs was detected by Western blot. $\beta$-actin was used as an internal loading control. B. and C. Inhibiting $\mathrm{PGE}_{2}$ signal pathway partly attenuated cell proliferation and drug resistance induced by COX-2 in TAMs. Breast cancer cells were first treated with or without EPs antagonists AH6809 $(5 \mu \mathrm{M})$ and AH23848 $(10 \mu \mathrm{M})$ for $12 \mathrm{~h}$ before co-cultured with or without TAMs transfected with adenoviral COX-2. Cell proliferation (B) and cell apoptosis (C) induced by ADM were measured by CCK-8 kit and flow cytometry respectively. D. Arginase activity (urea concentration) in macrophages transfected with adenoviral COX-2 or siRNA COX-2 or treated with $\mathrm{PGE}_{2}(1 \mu \mathrm{M})$ was analyzed by microplate reader. E. and F. Expression of IL-10 and IL-12/23 in macrophages was detected by ELISA. G. Expression of CD206 in macrophages was analyzed by flow cytometry. All the experiments were performed thrice in triplicate. Mean $\pm \mathrm{SD},{ }^{*} p<0.05$ and ${ }^{* *} p<0.01$. 
are well documented in breast cancer, and aberrant expressions of which are strongly associated with cell survival or resistance to chemotherapeutic drugs $[16,17]$. In order to identify whether or which Bcl-2 family members are involved in COX-2+ TAMs-induced breast cancer cell survival, the common anti-apoptotic proteins (Bcl-2 and $\mathrm{Bcl}-\mathrm{xl})$ and pro-apoptotic proteins (Bax, Bad and Bid) were detected by Western blot. TAMs induced Bcl-2 and decreased Bax expression in breast cancer cells (Figure 4A). Ectopic COX-2 expression significantly promoted, while COX-2 knockout in TAMs markedly abated, this effect (Figure 4B). In addition, TAMs increased the efflux of ADM and Rho 123 in cancer cells. Ectopic COX-2 expression in TAMs significantly reinforced, while inhibiting $\mathrm{COX}-2$ in TAMs attenuated, this effect (Figure 4C-4D). Because the ATP-binding cassette (ABC) transporters including P-glycoprotein (P-gp/ABCB1), multi-drug resistanceassociated protein 1 (MRP1/ABCC1), lung resistance protein (LRP), and breast cancer resistance protein (BCRP/ABCG2), are membrane proteins that couple the energy derived from ATP hydrolysis to extrude a variety of chemotherapeutic drugs out of the cancer cells [18], we examined the effect of COX-2 on expression of these proteins by Western blot. We found that P-gp but not other proteins was significantly increased in cancer cells co-cultured with TAMs (Figure 4E). The association of $\mathrm{P}$-gp expression in breast cancer cells and COX-2 in TAMs was validated by ectopic COX-2 expression and COX-2 knockdown in TAMs (Figure 4F). These results suggest that TAMs COX-2 enhances breast cancer cell survival by increasing Bcl-2 and $\mathrm{P}$-gp, and decreasing Bax in cancer cells.

\section{COX-2 in TAMs induces the expression of COX- 2 in breast cancer cells, which in turn, promotes macrophage polarization to $\mathrm{M} 2$ phenotype}

Over-expression of COX-2 in tumor cells is closely linked to cell survival, and it is suggested that TAMs are associated with high COX-2 expression in cancer cells [19-21]. In addition, $\mathrm{PGE}_{2}$ is also demonstrated to activate COX-2 expression with a positive feedback manner $[22,23]$. To investigate the mutual activation between COX-2 in different cell types, the expression of COX-2 in cancer cells and macrophages under different co-culture conditions was examined. We found that $\mathrm{COX}-2$ over-expression in TAMs enhanced COX-2 expression in breast cancer cells, while inhibiting COX-2 in TAMs attenuated this COX-2 induction in cancer cells (Figure 5A). Interestingly, $\mathrm{COX}-2$ in breast cancer cells was shown to activate $\mathrm{COX}-2$ in macrophages and induce $\mathrm{M} 2$ macrophage polarization (Figure $5 \mathrm{~B}-5 \mathrm{~F}$ ). These results suggest that COX-2 expressed in both TAMs and cancer cells forms a positive feedback loop for mediating communication between TAMs and cancer cells.

\section{COX-2 in TAMs enhances the activation of $\mathrm{PI3K} /$ Akt pathway in breast cancer cells}

TAMs activate PI3K/Akt pathway in cancer cells, and aberrant activation of the PI3K/Akt pathway is implicated in breast cancer cell proliferation and drug resistance [24-27]. Our results confirmed the activation of PI3K/Akt pathway in breast cancer cells co-cultured with TAMs. Moreover,

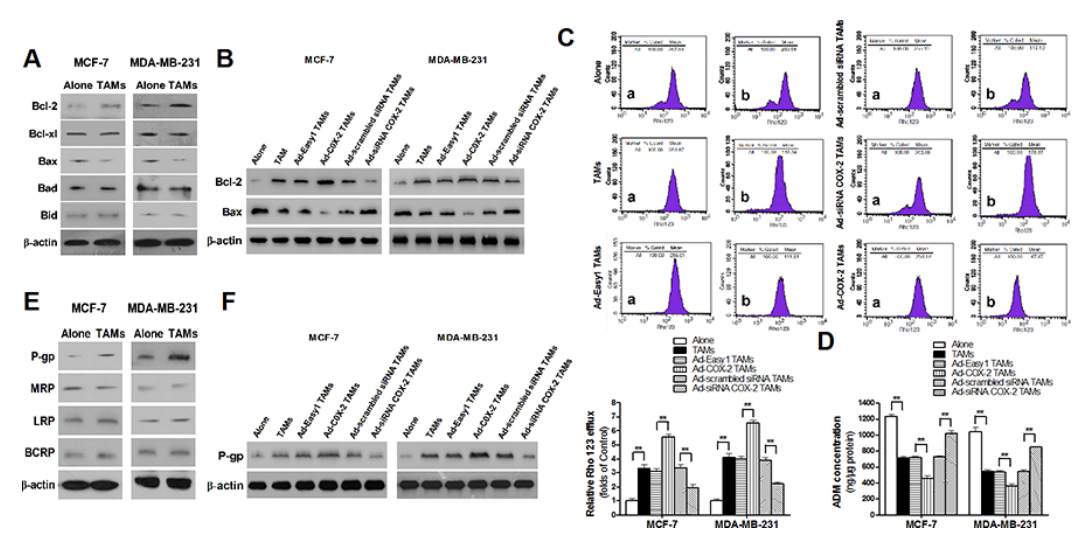

Figure 4: COX-2 in TAMs increases the expression of Bcl-2 and P-gp and decreases Bax expression in breast cancer cells. A. The expression of Bcl-2 family members in breast cancer cells co-cultured with or without TAMs was detected by Western blot. B. The expression of Bcl-2 and Bax in breast cancer cells co-cultured with or without TAMs transfected with adenoviral COX-2 or siRNA COX-2 was detected by Western blot. C. Rho 123 efflux in breast cancer cells was analyzed by flow cytometry. The panel shows Rho 123 efflux in MDA-MB-231 cells. a, intake amount; b, residue amount. Data were expressed as a ratio of treated cells to control (Alone) cells. Mean $\pm \mathrm{SD}, n=9, * * p<0.01$. D. The concentration of ADM in human breast cancer cells was measured by spectrophotometer. Mean $\pm \mathrm{SD}$, $n=9, * * p<0.01$. E. The expression of MDR related proteins in breast cancer cells co-cultured with or without TAMs was detected by Western blot. F. The expression of P-gp in breast cancer cells co-cultured with or without TAMs transfected with adenoviral COX-2 or siRNA COX-2 was detected by Western blot. In all Western blot assays, $\beta$-actin was used as an internal loading control, and the blots shown are representative of six independent experiments. 

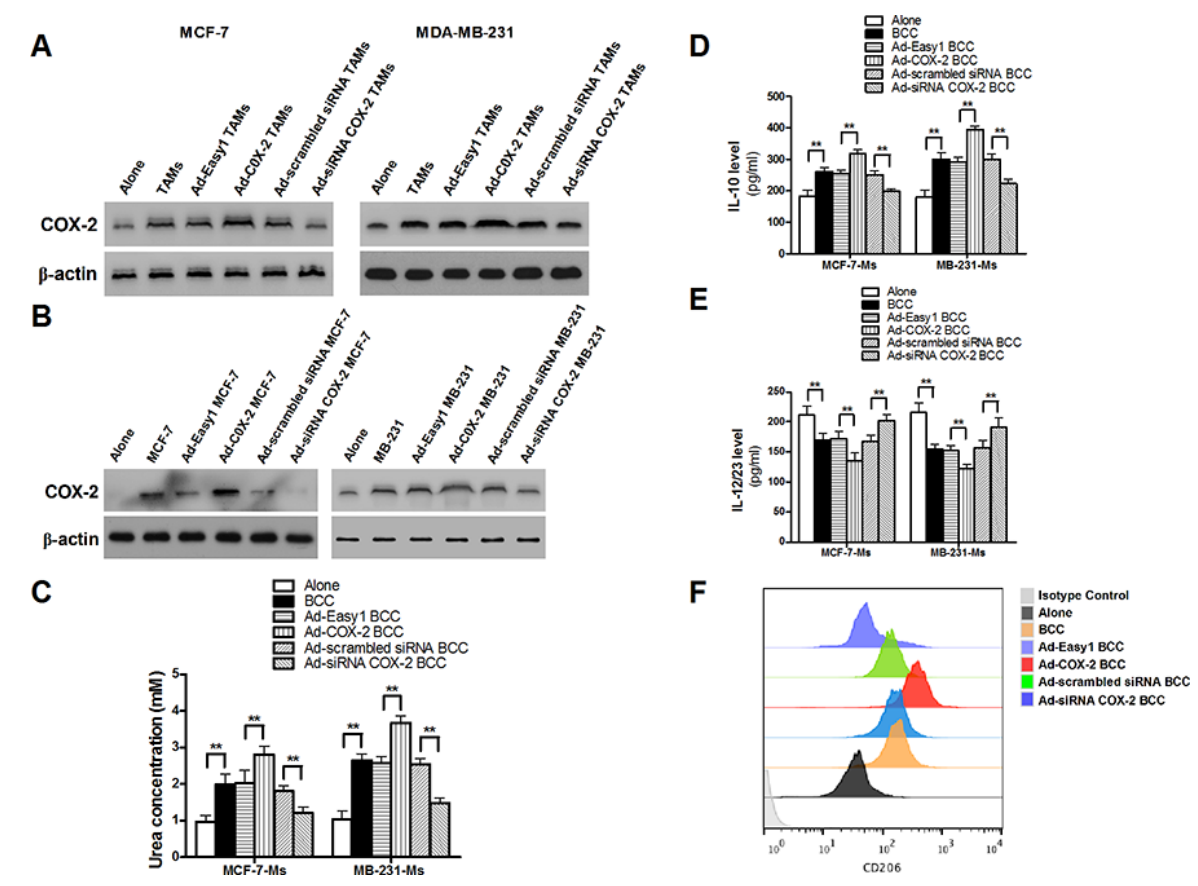

Figure 5: COX-2 in TAMs induces the expression of COX-2 in breast cancer cells, which in turn, promotes macrophage polarization to $\mathrm{M} 2$ phenotype. A. The expression of COX-2 in breast cancer cells co-cultured with or without TAMs transfected with adenoviral COX-2 or siRNA COX-2 was detected by Western blot. B. The expression of COX-2 in macrophages co-cultured with or without breast cancer cells transfected with adenoviral COX-2 or siRNA COX-2 was detected by Western blot. In all Western blot assays, $\beta$-actin was used as an internal loading control, and the blots shown are representative of six independent experiments. C. Arginase activity (urea concentration) in macrophages co-cultured with or without breast cancer cells transfected with adenoviral COX-2 or siRNA COX-2 was analyzed by microplate reader. D. and E. Expression of IL-10 and IL-12/23 in macrophages was detected by ELISA. F. Expression of CD206 in macrophages co-cultured with breast cancer cells (MDA-MB-231 cells) was analyzed by flow cytometry. All the experiments were performed thrice in triplicate. Mean $\pm \mathrm{SD},{ }^{*} p<0.05$ and ${ }^{*} p<0.01$.

COX-2 over-expression in TAMs enhanced the activation of PI3K/Akt pathway in breast cancer cells, while inhibiting COX-2 by siRNA suppressed this effect (Figure 6A). Among, the three Akt isoforms, Akt1 is the most widely expressed and the best studied one in cancer progression [28-30]. Blocking Akt1 in cancer cells suppressed the pro-survival effects of the $\mathrm{COX}-2^{+}$TAMs on breast cancer cells (Figure 6B-6C). Meanwhile, down-regulation of Akt1 resulted in the suppression of Bcl-2, P-gp and COX-2, and increase of Bax expression in breast cancer cells (Figure 6D). These results strongly suggest that activation of the PI3K/ Akt pathway is closely involved in COX-2+ TAMs-induced pro-tumor activity in breast cancer cells.

\section{DISCUSSION}

TAMs have been shown to promote tumor growth, angiogenesis, invasion and metastasis in many cancer types. TAMs are generally thought to more closely resemble the M2-polarized phenotype [2, 6]. Here, we demonstrate that COX-2 is abundantly expressed in breast TAMs and correlates with poor prognosis in patients with breast cancer. COX is an enzyme that converts arachidonic acid into prostaglandin endoperoxide. Two isoforms of COX have been described. COX-1 is constitutively expressed in normal adult human tissues. In contrast, COX-2 is absent or expressed at low levels in normal human tissues, but is induced in endothelial cells, monocytes, and tumor cells by cytokines, growth factors, hormones, or tumor promoters [31]. Accumulating evidence shows that COX-2 is over-expressed in breast cancer cells and is closely associated with cell proliferation, metastasis, angiogenesis and immune regulation [32, 33]. In addition, high level of COX-2 was also prevalent in other components of tumor microenvironment such as fibroblasts, myeloid cells and vascular endothelial cells, and may contribute to malignant tumor progression [34-36]. In our study, we found that over-expression of COX-2 in breast TAMs promoted breast cancer cell proliferation and survival. More importantly, COX-2 exerted an effect on the pro-tumor potential of TAMs. These results indicate that high expression of COX-2 in the tumor microenvironment exerts great influence on cancer progression.

As the principle $\mathrm{COX}-2$ product, $\mathrm{PGE}_{2}$ plays a critical role in the biological function of COX-2 in tumors. $\mathrm{PGE}_{2}$ has been implicated in various breast cancer processes via activating PKC, PKA or TGF- $\beta$ signal pathways through specific $\mathrm{PGE}_{2}$ receptors [15]. 


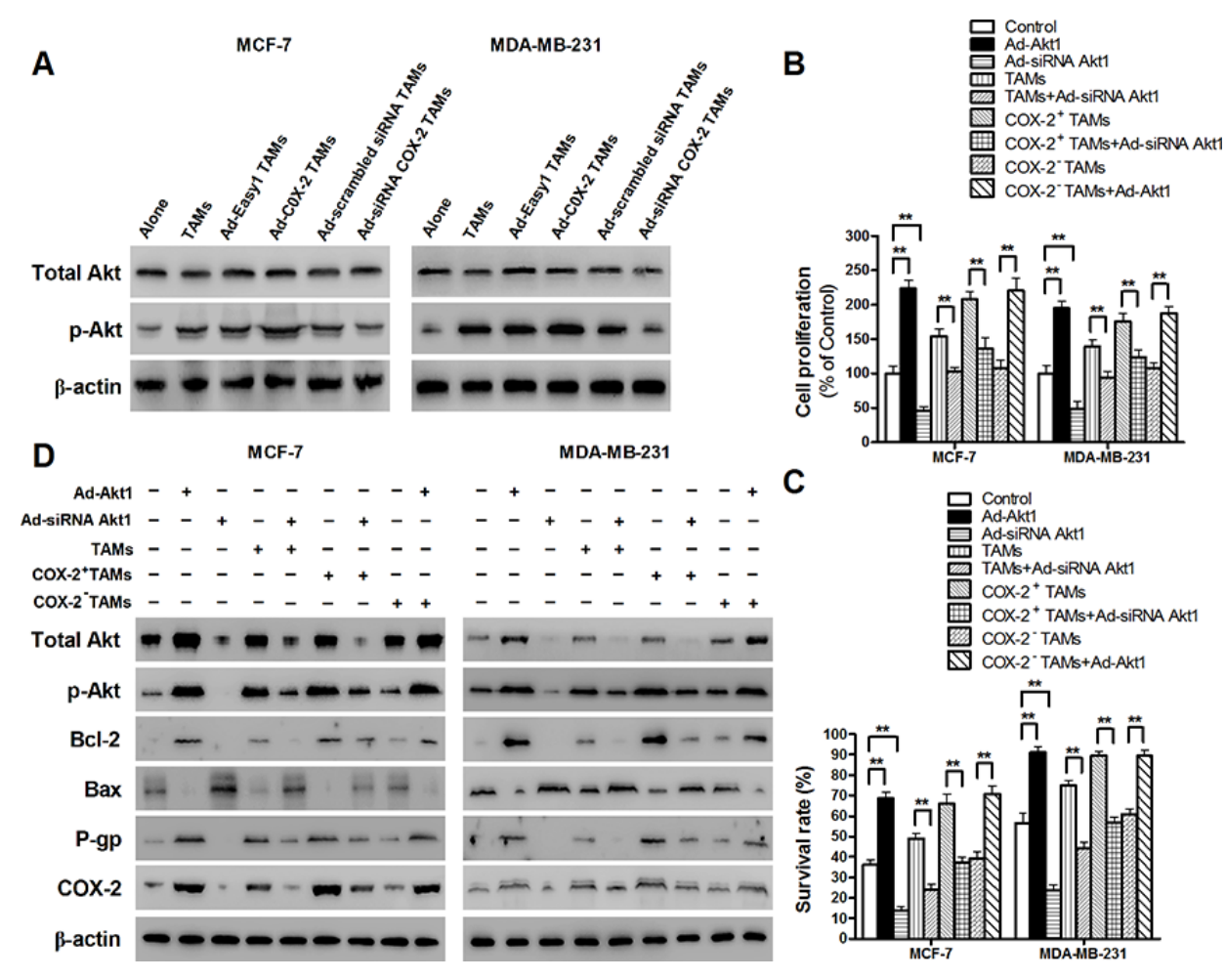

Figure 6: COX-2 in TAMs enhanced the activation of PI3K/Akt pathway in breast cancer cells. A. The activation of Akt in breast cancer cells co-cultured with or without TAMs transfected with adenoviral COX-2 or siRNA COX-2 was detected by Western blot. B. and C. Inhibiting Akt1 in breast cancer cells attenuated cell proliferation and drug resistance induced by COX-2 in TAMs. Breast cancer cells transfected with adenoviral siRNAAkt1 or Akt1 were co-cultured with or without TAMs transfected with adenoviral COX-2 or siRNA COX-2. Cell proliferation (B) and cell apoptosis (C) induced by ADM were measured by CCK-8 kit and flow cytometry, respectively. D. Inhibiting Akt1 resulted in the suppression of Bcl-2, P-gp and COX-2, and increase of Bax expression in breast cancer cells co-cultured with COX-2 $2^{+}$TAMs. The expression of related proteins in breast cancer cells was detected by Western blot. $\beta$-actin was used as an internal loading control, and the blots shown are representative of six independent experiments.

However, our study showed that inhibiting the $\mathrm{PGE}_{2}$ signal transduction in breast cancer cells only partly attenuated pro-tumor effect induced by COX-2 in TAMs, suggesting that $\mathrm{PGE}_{2}$ was not the only direct mediator involved in the process. It was reported that COX-2 inhibition caused loss of the M2 macrophage characteristics in TAMs, which may assist to prevent breast cancer metastasis in a murine breast cancer model [37]. Furthermore, $\mathrm{PGE}_{2}$ is typically associated with immunosuppression, restraint of M1 macrophage polarization, as well as enhanced expression of M2 markers [38-40]. Consistent with the reports, we confirmed that COX-2 was indeed an essential factor for the induction and maintenance of $\mathrm{M} 2$ polarity in human breast TAMs. COX-2 in TAMs may also exert its protumor effect by increasing various pro-tumor cytokines release from TAMs. Further studies are needed to identify the involved cytokines and elucidate the underlying mechanisms.

TAMs have been shown to induce cell proliferation and inhibit apoptosis in many kinds of malignant tumors such as sarcoma, lymphoma, colon and breast cancers [4, 41-43]. Enhanced stemness of cancer cells by cytokines (e.g. TGF- $\beta$ and IL-1 $\beta$ ) from TAMs may contribute to the pro-tumor activities of TAMs $[43,44]$. In addition, TAMs can promote cell survival and resistance to chemotherapeutic treatment through regulating Bcl-2 family members and drug-resistance factors in cancer cells $[45,46]$. In our study, we found that TAMs induced breast cancer cell survival by up-regulating Bcl-2 and p-gp and down-regulating Bax expression. It has been shown that $\mathrm{COX}-2$ can regulate the expression of Bcl-2 family members and drug-resistance proteins in breast cancer cells [47-50]. Our study indicated that COX-2 in TAMs was involved in the regulating function of TAMs on Bcl-2 family members and p-gp in cancer cells. Moreover, we found that there was a positive COX-2mediated feedback loop between TAMs and breast cancer cells, which may play a key role in tumor microenvironment reprogramming and thus cancer progression.

PI3K/Akt signaling pathway promotes cancer cell survival by modulating Bcl-2 members and drugresistance proteins. Bcl-2, Bax and p-gp are all regarded as the downstream signal molecules of the PI3K/Akt pathway [51, 52]. The activation of PI3K/Akt pathway in cancer cells is a central event in TAMs-mediated cancer progression, as chemokines or cytokines secreted from TAMs may be the effective PI3K/Akt activators $[24,26,53] . \mathrm{PGE}_{2}$ was reported to inhibit apoptosis in human cancer cells through $\mathrm{PI} 3 \mathrm{~K} / \mathrm{Akt}$ activation. 


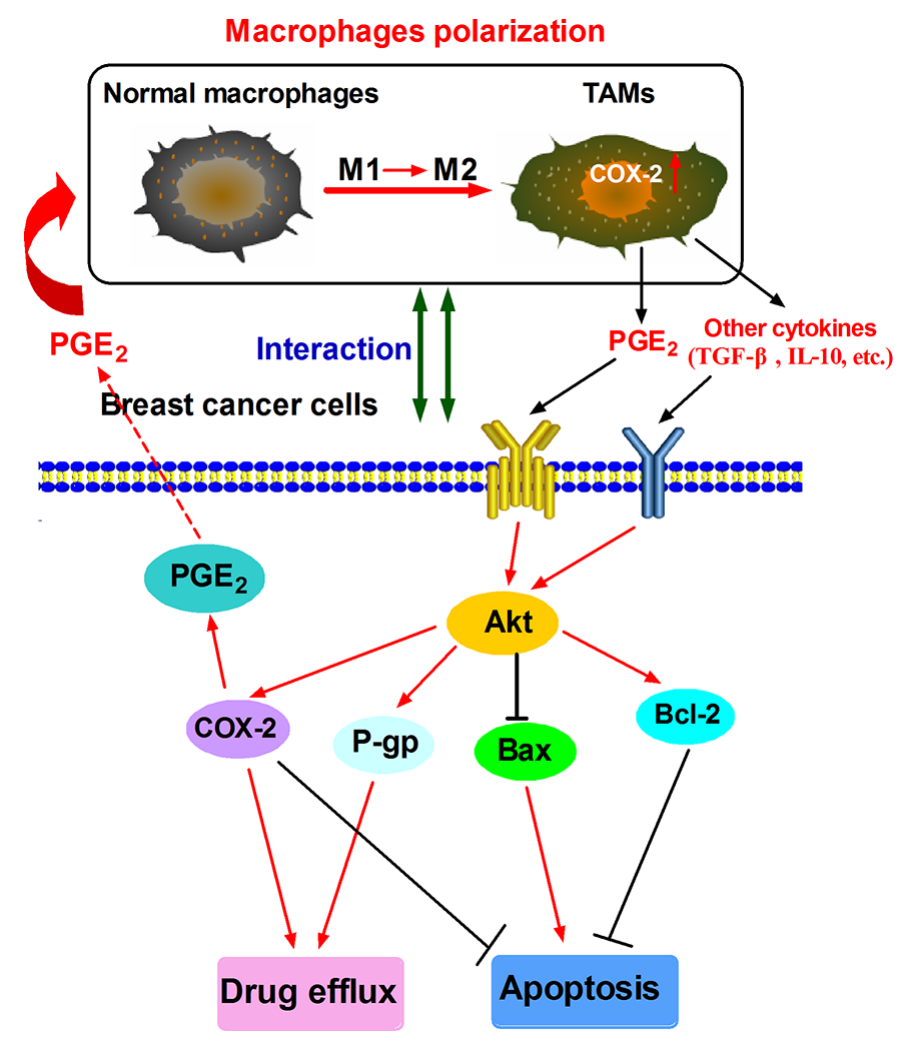

Figure 7: Proposed mechanistic model showing COX-2 $2^{+}$TAMs-induced cell survival in breast cancer.

Furthermore, $\mathrm{COX}-2 / \mathrm{PGE}_{2}$ was shown to promote the activation of PI3K/Akt pathway that is a part of the positive feedback loop to maintain an active prosurvival COX-2/PGE 2 pathway in cancer cells [54-57]. Additionally, other cytokines (TGF- $\beta$, IL-10, CCL18, etc.) which can be released from TAMs also have the ability to promote tumor progression through the PI3K/Akt pathway [58-60]. All these factors could contribute to $\mathrm{COX}-2^{+}$ TAMs-induced PI3K/Akt activation in breast cancer cells, which warrants further studies.

In summary, our studies shows that COX-2, abundantly expressed in TAMs, is important for macrophages polarization and breast cancer cell survival (Fig. 7). Future studies are needed to investigate the detailed mechanism by which $\mathrm{COX}-2 / \mathrm{PGE}_{2}$ influences the tumor microenvironment. Accumulating evidence suggests COX-2 inhibitors are potential anticancer therapeutic agents [61]. Studies on the emerging roles within the $\mathrm{COX}-2 / \mathrm{PGE}_{2}$ pathway in tumor microenvironment may reveal novel approaches or molecular targets for both cancer chemoprevention and therapy.

\section{MATERIALS AND METHODS}

\section{Clinical data collection}

Breast cancer tissue microarrays (HBre-Duc 170Sur-01, Outdo Biotech Co., Shanghai, China) include primary breast carcinoma samples from 160 patients with a median age of 53 years and a median follow-up period of 118 months at the hospitals in central China. Every sample dot with a diameter of $1.5 \mathrm{~mm}$ and a thickness of $4 \mu \mathrm{m}$ was prepared according to a standard method. All samples were collected with informed consent from patients, and all related procedures were performed with the approval of ethics boards of the indicated hospitals.

\section{Generation of macrophages or tumor associated macrophages}

Mononuclear cells from the blood of healthy donors were incubated in 6-well plates for 2 hours at $37^{\circ} \mathrm{C}$ to remove non-adherent cells. The adherent monocytes were incubated for 7 days in medium with $\mathrm{M}$-CSF to become normal macrophages (monocytederived macrophages, MDMs). MDMs were co-cultured with breast cancer cells for an additional 7 days to generate tumor associated macrophages (TAMs) [46].

\section{Isolation of TAMs from tumor tissues by magnetic-activated cell sorting}

Tumor tissues were minced into small pieces and then incubated for $1 \mathrm{~h}$ at $37^{\circ} \mathrm{C}$ in $5 \mathrm{ml}$ of HBSS $(10 \%$ fetal calf serum) containing $125 \mathrm{U} / \mathrm{ml}$ of collagenase I (Invitrogen, CA, USA), $60 \mathrm{U} / \mathrm{ml}$ of Dnase 
I and $60 \mathrm{U} / \mathrm{ml}$ of hyaluronidase (Sigma, St Louis, MO, USA). Supernatants were harvested and then depleted of RBC with ACK. Cell suspensions were passed through a fine screen mesh and then several times through a ${ }^{\#} 25$ needle. Cell pellets were resuspended and labeled with biotinylated mouse anti-human CD163 antibody (Abcam, Cambridge, MA, USA) using $0.2 \mu \mathrm{g} / 1 \times 10^{6}$ cells in 100 $\mathrm{ml}$ staining buffer. Streptavidin microbeads were added at $10 \mathrm{ml}$ per $10^{7}$ cells and then incubated $15 \mathrm{~min}$ at $4^{\circ} \mathrm{C}$. Cells were re-suspended in $500 \mathrm{ml}$ of separating buffer and applied to an LS column in a magnetic field (Miltenyi Biotec, Bergisch Gladbach, Germany). Unlabeled cells that passed through the column were collected, as were retained cells after removal of the magnetic field [62].

\section{Arginase activity assay}

The arginase activity was measured as previously described [63]. Briefly, the cell lysate was activated by heating for $10 \mathrm{~min}$ at $56^{\circ} \mathrm{C}$. L-arginine hydrolysis was conducted by incubating the activated lysate with $0.5 \mathrm{M}$ L-arginine ( $\mathrm{pH} 9.7$ ) at $37^{\circ} \mathrm{C}$ for 15 to $120 \mathrm{~min}$. The reaction was stopped with $\mathrm{H}_{2} \mathrm{SO} 4(96 \%) / \mathrm{H}_{3} \mathrm{PO} 4(85 \%) / \mathrm{H}_{2} \mathrm{O}$ (1:3:7, v/v/v, VWR). $\alpha$-isonitrosopropiophenone (ISPF) dissolved in $100 \%$ ethanol (Sigma, St Louis, MO, USA) was added and incubated for $45 \mathrm{~min}$ at $100^{\circ} \mathrm{C}$, followed by 30 min at $4^{\circ} \mathrm{C}$. A standard curve was obtained by treating serially diluted urea with ISPF and incubated in the final step. The optical density (OD) was measured at $550 \mathrm{~nm}$. Protein concentration of samples was measured using the BCA Protein Assay kit (Pierce, Rockford, USA). One unit of enzyme activity is defined as the amount of enzyme that catalyzes the formation of $1 \mu \mathrm{mol}$ of urea per min.

\section{ELISA and EIA}

The levels of IL-10 and IL-12/23 p40 in macrophages were determined by ELISA using human ELISA Kits, according to the manufacturers' instruction (R\&D Systems, Minneapolis, MN, USA). The $\mathrm{PGE}_{2}$ amount in macrophages was determined by EIA kits, according to the manufacturers' instruction (Cayman Chemical, Ann Arbor, Michigan USA).

\section{Quantitative reverse transcription polymerase chain reaction}

Real-time PCR was carried out in ABI 7500 RealTime PCR System (Applied Biosystems) by using Maxima SYBR Green/ROX qPCR Master Mix (MBI Fermentas, St. Leon-Rot, Germany). Primer pairs were as follows: (a) COX-2, 5'- TCCCTGAGCATCTACGGTT-3' (forward) and 5'-CATCGCATACTGTTGTGTTC - $3^{\prime}$ (reverse); and (b) $\beta$-actin, 5'-CCTGTGGCATCCACGAAACT-3' (forward) and 5'- GAAGCATTTGCGGTGGACGAT-3' (reverse), encoding products of 185 and $314 \mathrm{bp}$, respectively. Thermal cycling conditions were $95^{\circ} \mathrm{C}$ for $30 \mathrm{sec}$, followed by $5 \mathrm{sec}$ at $95^{\circ} \mathrm{C}, 1 \mathrm{~min}$ at $60^{\circ} \mathrm{C}$ for 40 cycles. Melting-curve analysis and agarose gel electrophoresis of PCR products were further performed. Relative expression levels of COX-2 in cells were standardized to $\beta$-actin levels.

\section{Adenovirus infection}

The adenovirus expressing empty Ad-Easy 1 vector, COX-2, Akt1, scrambled siRNA or siRNA COX-2 or Akt1 was used following the procedure described previously [64]. Target sequences of the siRNA specific for COX-2 and Akt1 are as follows: siRNA-COX-2, 5'-AACCGAGGTGTATGTATGAGTGT-3'; siRNAAkt1, 5'-TCGTGCCATGATCTGTATTTAAT-3'. In addition to the expression of transgenes, the adenovirus expressing system also expressed RFP as amarker for monitoring transfection efficiency. A series of infections using various dilutions of adenovirus were conducted to determine the optimal multiplicity of infection (MOI) in which expression of target genes occurred with low cytotoxicity.

\section{Cell proliferation/viability assay}

Cells seeded into a 96-well plate at 4000 cells/well were treated with or without different concentrations of chemotherapeutic drugs and incubated for $48 \mathrm{~h}$. Cell viability was measured according to the protocol of CCK-8 (KeyGEN Biotech, Nanjing, China). All plates had control wells containing medium without cells to obtain a value for background spectrometric absorbance which was subtracted from the test sample readings. Data were expressed as ratios of treated to control cells, mean $\pm \mathrm{SD}$ for three replications.

\section{Flow cytometry analysis of cell apoptosis}

For apoptosis analysis, Annexin V-FITC/propidium iodide (PI) staining (KeyGEN Biotech, Nanjing, China) was performed by Elite ESP flow cytometry according to the manufacturer's guidelines.

\section{Animal experiments}

All the animal studies were approved by the Animal Ethics Committee of Chongqing Medical University. 5-Week old severe combined immunodeficiency (SCID) hairless female mice were purchased (Institute of Laboratory Animal Science, Chinese Academy of Medical Science, Beijing, China) and randomly divided into four groups of 10 mice each. All the mice were housed according to the national and institutional guidelines for humane animal care. Macrophages in mice were depleted by injection of freshly prepared clodronate-containing liposomes as described [62]. At 6 weeks of age, the mice were injected subcutaneously on the right rear flanks with $4 \mathrm{~T} 1$ cells that were prior 
admixed with COX-2 over-expression, COX-2 knockdown or wild-type RAW264.7-derived TAMs, respectively. Body weights were monitored weekly as an indicator of overall health. After 4 weeks, the mice were euthanized via $\mathrm{CO}_{2}$ asphyxiation. Tumors were then removed, weighed, and sent for immunohistochemistry (IHC) analysis.

\section{Indirect immunofluorescence analysis}

For the immunofluorescence experiments, paraffin embedded tissues were prepared and analyzed under fluorescence microscope following the procedure described previously [65]. Briefly, samples were incubated with primary mouse antibody against CD163 and rabbilt antibody against COX-2, and then incubated with DyLight 488 against mouse IgG or DyLight 549 secondary antibody against rabbit IgG (Cwbiotech, Beijing, China). Cells were then counterstained with DAPI and imaged with a fluorescence microscope (Leica DM IRB).

\section{IHC}

Tumor tissues were fixed in $4 \%$ formaldehyde solution ( $\mathrm{pH} 7.0)$ and subsequently embedded in paraffin. Immunohistochemical studies were performed using the standard streptavidin-peroxidase (SP) method with the UltraSensitive TM SP Kit (Maixin-Bio, Fujian, China) according to the manufacturer's instructions. Tumor specimens were stained using Ki-67 antibody (Maixin-Bio, Fujian, China) for cell proliferation and cleaved caspase 3 antibody (Cell Signaling Technology, Inc., Danvers, MA) for apoptosis. Negative control was performed by replacing the primary antibody with PBS. Immunostained slides were blindly evaluated by a trained pathologist under a transmission light microscope.

\section{Western blot}

Cell lysate was prepared according to the method described by the protein extract kit (Active Motif Company, Carlsbad, USA). Protein concentrations were determined by BCA protein assay kit (Pierce Biotechnology Inc, Rockford, USA). Cell lysate was analyzed for Western blot analysis using EP1, EP2, EP3, EP4, Bcl-2, Bcl-xl, Bax, Bad, Bid, P-gp, MRP1, LRP, BCRP, COX-2, total and phosphor(p)-Akt plus $\beta$-actin (Detailed information about antibodies is shown in Supplementary Table S1). Antibody binding was visualized with an ECL chemiluminescence system and short exposure of the membrane to X-ray films (Kodak, Japan). Densitometric analysis was done using Image Pro-Plus software and normalized to $\beta$-actin.

\section{Rhodamine (Rho) 123 efflux assay}

Rho123 was added to $1 \times 10^{6} / \mathrm{ml}$ cells at the final concentration of $1 \mu \mathrm{g} / \mathrm{ml}$, and incubated at $37^{\circ} \mathrm{C}$ for $1 \mathrm{~h}$. After washing with PBS for 3 times, intracellular Rho123 was determined by flow cytometry. The cells above washed by PBS for 3 times were resuspended and then cultured with 1640 medium without Rho123 for 2 h. After washing with PBS for 3 times, intracellular Rho123 was determined by flow cytometry.

\section{Intracellular adriamycin accumulation assay}

Cells were first incubated with 1640 medium containing $10 \mu \mathrm{g} / \mathrm{ml} \mathrm{ADM}$ at $37^{\circ} \mathrm{C}$ for $1 \mathrm{~h}$. After washing with PBS for 3 times, the cells were resuspended and then cultured with 1640 medium without adriamycin (ADM) for $2 \mathrm{~h}$. After washing with PBS for 3 times, intracellular ADM was measured by fluorescence spectrophotometer.

\section{Statistical analysis}

All statistical analysis was done using SPSS 18.0 software. Chi-square test was applied to analyze the relationship between COX $-2^{+}$TAMs counts and clinicopathological status. Pearson's correlation and regression analysis was performed to assess the relationship between $\mathrm{COX}-2^{+}$TAMs and $\mathrm{Ki}-67$ or COX-2 in the enrolled samples. Kaplan-Meier survival curves were plotted, and log rank test was done. The significance of various variables for survival was analyzed by the Cox proportional hazards model in a multivariate analysis. The data in cell experiments were presented as the mean values \pm standard deviation (SD). Differences were considered significant when the $p$ values were 0.05 .

\section{ACKNOWLEDGMENTS}

This study was supported by National Natural Science Foundation of China (NO. 81102007 and NO. 81472475), the International S\&T Cooperation Program of China (ISTCP) (2012DFA10650), and National High Technology Research and Development Program of China (863 Program) (2012AA020101).

\section{CONFLICTS OF INTEREST}

The authors declare no conflict of interest in this study.

\section{REFERENCES}

1. Goubran HA, Kotb RR, Stakiw J, Emara ME, Burnouf T. Regulation of tumor growth and metastasis: the role of tumor microenvironment. Cancer Growth Metastasis. 2014; 7:9-18.

2. Ramanathan S, Jagannathan N. Tumor associated macrophage: a review on the phenotypes, traits and functions. Iran J Cancer Prev. 2014; 7:1-8. 
3. Ostuni R, Kratochvill F, Murray PJ, Natoli G. Macrophages and cancer: from mechanisms to therapeutic implications. Trends Immunol. 2015.

4. Tang X. Tumor-associated macrophages as potential diagnostic and prognostic biomarkers in breast cancer. Cancer Lett. 2013; 332:3-10.

5. Medrek C, Ponten F, Jirstrom K, Leandersson K. The presence of tumor associated macrophages in tumor stroma as a prognostic marker for breast cancer patients. BMC Cancer. 2012; $12: 306$.

6. Sica A, Larghi P, Mancino A, Rubino L, Porta C, Totaro MG, Rimoldi M, Biswas SK, Allavena P, Mantovani A. Macrophage polarization in tumour progression. Semin Cancer Biol. 2008; 18:349-355.

7. Cook J, Hagemann T. Tumour-associated macrophages and cancer. Curr Opin Pharmacol. 2013; 13:595-601.

8. Vendramini-Costa DB, Carvalho JE. Molecular link mechanisms between inflammation and cancer. Curr Pharm Des. 2012; 18:3831-3852.

9. Misra S, Sharma K. COX-2 signaling and cancer: new players in old arena. Curr Drug Targets. 2014; 15:347-359.

10. Ghosh N, Chaki R, Mandal V, Mandal SC. COX-2 as a target for cancer chemotherapy. Pharmacol Rep. 2010; 62:233-244.

11. Khan Z, Khan N, Tiwari RP, Sah NK, Prasad GB, Bisen PS. Biology of Cox-2: an application in cancer therapeutics. Curr Drug Targets. 2011; 12:1082-1093.

12. Greenhough A, Smartt HJ, Moore AE, Roberts HR, Williams AC, Paraskeva C, Kaidi A. The COX-2/PGE2 pathway: key roles in the hallmarks of cancer and adaptation to the tumour microenvironment. Carcinogenesis. 2009; 30:377-386.

13. Bianchini F, Massi D, Marconi C, Franchi A, Baroni G, Santucci M, Mannini A, Mugnai G, Calorini L. Expression of cyclo-oxygenase-2 in macrophages associated with cutaneous melanoma at different stages of progression. Prostaglandins Other Lipid Mediat. 2007; 83:320-328.

14. Tsai CS, Chen FH, Wang CC, Huang HL, Jung SM, Wu CJ, Lee CC, McBride WH, Chiang CS, Hong JH. Macrophages from irradiated tumors express higher levels of iNOS, arginase-I and COX-2, and promote tumor growth. Int J Radiat Oncol Biol Phys. 2007; 68:499-507.

15. Reader J, Holt D, Fulton A. Prostaglandin E2 EP receptors as therapeutic targets in breast cancer. Cancer Metastasis Rev. 2011; 30:449-463.

16. Thomadaki H, Scorilas A. Molecular profile of the BCL2 family of the apoptosis related genes in breast cancer cells after treatment with cytotoxic/cytostatic drugs. Connect Tissue Res. 2008; 49:261-264.

17. Barille-Nion S, Bah N, Vequaud E, Juin P. Regulation of cancer cell survival by BCL2 family members upon prolonged mitotic arrest: opportunities for anticancer therapy. Anticancer Res. 2012; 32:4225-4233.

18. Choi $\mathrm{YH}, \mathrm{Yu} \mathrm{AM}$. ABC transporters in multidrug resistance and pharmacokinetics, and strategies for drug development. Curr Pharm Des. 2014; 20:793-807.

19. Hou Z, Falcone DJ, Subbaramaiah K, Dannenberg AJ. Macrophages induce COX-2 expression in breast cancer cells: role of IL-1beta autoamplification. Carcinogenesis. 2011; 32:695-702.

20. Naghshvar F, Torabizadeh Z, Emadian O, Enami K, Ghahremani M. Correlation of cyclooxygenase 2 expression and inflammatory cells infiltration in colorectal cancer. Pak J Biol Sci. 2009; 12:98-100.

21. Chen WT, Hung WC, Kang WY, Huang YC, Su YC, Yang $\mathrm{CH}$, Chai $\mathrm{CY}$. Overexpression of cyclooxygenase-2 in urothelial carcinoma in conjunction with tumorassociated-macrophage infiltration, hypoxia-inducible factor-1alpha expression, and tumor angiogenesis. APMIS. 2009; 117:176-184.

22. Yoshida K, Fujino H, Otake S, Seira N, Regan JW, Murayama T. Induction of cyclooxygenase-2 expression by prostaglandin E2 stimulation of the prostanoid EP4 receptor via coupling to Galphai and transactivation of the epidermal growth factor receptor in HCA-7 human colon cancer cells. Eur J Pharmacol. 2013; 718:408-417.

23. Pink RC, Bailey TA, Iputo JE, Sammon AM, Woodman AC, Carter DR. Molecular basis for maize as a risk factor for esophageal cancer in a South African population via a prostaglandin E2 positive feedback mechanism. Nutr Cancer. 2011; 63:714-721.

24. Su S, Liu Q, Chen J, Chen F, He C, Huang D, Wu W, Lin L, Huang W, Zhang J, Cui X, Zheng F, Li H, et al. A positive feedback loop between mesenchymal-like cancer cells and macrophages is essential to breast cancer metastasis. Cancer Cell. 2014; 25:605-620.

25. Cardoso AP, Pinto ML, Pinto AT, Oliveira MI, Pinto MT, Goncalves R, Relvas JB, Figueiredo C, Seruca R, Mantovani A, Mareel M, Barbosa MA, Oliveira MJ. Macrophages stimulate gastric and colorectal cancer invasion through EGFR Y(1086), c-Src, Erk1/2 and Akt phosphorylation and smallGTPase activity. Oncogene. 2014; 33:2123-2133.

26. Nabeshima A, Matsumoto Y, Fukushi J, Iura K, Matsunobu T, Endo M, Fujiwara T, Iida K, Fujiwara Y, Hatano M, Yokoyama N, Fukushima S, Oda Y, et al. Tumour-associated macrophages correlate with poor prognosis in myxoid liposarcoma and promote cell motility and invasion via the HB-EGF-EGFR-PI3K/Akt pathways. Br J Cancer. 2015; 112:547-555.

27. Paplomata E, O'Regan R. The PI3K/AKT/mTOR pathway in breast cancer: targets, trials and biomarkers. Ther Adv Med Oncol. 2014; 6:154-166. 
28. Vivanco I, Sawyers CL. The phosphatidylinositol 3-Kinase AKT pathway in human cancer. Nat Rev Cancer. 2002; 2:489-501.

29. Toker A, Marmiroli S. Signaling specificity in the Akt pathway in biology and disease. Adv Biol Regul. 2014; 55:28-38.

30. Wickenden JA, Watson CJ. Key signalling nodes in mammary gland development and cancer. Signalling downstream of PI3 kinase in mammary epithelium: a play in 3 Akts. Breast Cancer Res. 2010; 12:202.

31. Simmons DL, Botting RM, Hla T. Cyclooxygenase isozymes: the biology of prostaglandin synthesis and inhibition. Pharmacol Rev. 2004; 56:387-437.

32. Singh-Ranger G, Salhab M, Mokbel K. The role of cyclooxygenase-2 in breast cancer: review. Breast Cancer Res Treat. 2008; 109:189-198.

33. Jana D, Sarkar DK, Ganguly S, Saha S, Sa G, Manna AK, Banerjee A, Mandal S. Role of Cyclooxygenase 2 (COX-2) in Prognosis of Breast Cancer. Indian J Surg Oncol. 2014; 5:59-65.

34. Erez N, Glanz S, Raz Y, Avivi C, Barshack I. Cancer associated fibroblasts express pro-inflammatory factors in human breast and ovarian tumors. Biochem Biophys Res Commun. 2013; 437:397-402.

35. Chen EP, Markosyan N, Connolly E, Lawson JA, Li X, Grant GR, Grosser T, FitzGerald GA, Smyth EM. Myeloid Cell COX-2 deletion reduces mammary tumor growth through enhanced cytotoxic T-lymphocyte function. Carcinogenesis. 2014; 35:1788-1797.

36. Bhattacharjee RN, Timoshenko AV, Cai J, Lala PK. Relationship between cyclooxygenase- 2 and human epidermal growth factor receptor 2 in vascular endothelial growth factor $C$ up-regulation and lymphangiogenesis in human breast cancer. Cancer Sci. 2010; 101:2026-2032.

37. Na YR, Yoon YN, Son DI, Seok SH. Cyclooxygenase-2 inhibition blocks M2 macrophage differentiation and suppresses metastasis in murine breast cancer model. PLoS One. 2013; 8:e63451.

38. Liu L, Ge D, Ma L, Mei J, Liu S, Zhang Q, Ren F, Liao H, $\mathrm{Pu} \mathrm{Q}$, Wang T, You Z. Interleukin-17 and prostaglandin E2 are involved in formation of an M2 macrophage-dominant microenvironment in lung cancer. J Thorac Oncol. 2012; 7:1091-1100.

39. Heusinkveld M, de Vos van Steenwijk PJ, Goedemans R, Ramwadhdoebe TH, Gorter A, Welters MJ, van Hall T, van der Burg SH. M2 macrophages induced by prostaglandin E2 and IL-6 from cervical carcinoma are switched to activated M1 macrophages by CD4+ Th1 cells. J Immunol. 2011; 187:1157-1165.

40. Ylostalo JH, Bartosh TJ, Coble K, Prockop DJ. Human mesenchymal stem/stromal cells cultured as spheroids are self-activated to produce prostaglandin E2 that directs stimulated macrophages into an anti-inflammatory phenotype. Stem Cells. 2012; 30:2283-2296.
41. Evans R, Duffy T, Cullen RT. Tumor-associated macrophages stimulate the proliferation of murine tumor cells surviving treatment with the oncolytic cyclophosphamide analogue Asta Z-7557: in vivo implications. Int J Cancer. 1984; 34:883-890.

42. Liu Y, Fan L, Wang Y, Li P, Zhu J, Wang L, Zhang W, Zhang Y, Huang G. Tumor-associated macrophages promote tumor cell proliferation in nasopharyngeal NK/T-cell lymphoma. Int J Clin Exp Pathol. 2014; 7:5429-5435.

43. Kaler P, Galea V, Augenlicht L, Klampfer L. Tumor associated macrophages protect colon cancer cells from TRAILinduced apoptosis through IL-1beta-dependent stabilization of Snail in tumor cells. PLoS One. 2010; 5:e11700.

44. Fan QM, Jing YY, Yu GF, Kou XR, Ye F, Gao L, Li R, Zhao QD, Yang Y, Lu ZH, Wei LX. Tumor-associated macrophages promote cancer stem cell-like properties via transforming growth factor-beta1-induced epithelialmesenchymal transition in hepatocellular carcinoma. Cancer Lett. 2014; 352:160-168.

45. Yang C, He L, He P, Liu Y, Wang W, He Y, Du Y, Gao F. Increased drug resistance in breast cancer by tumor-associated macrophages through IL-10/STAT3/bcl-2 signaling pathway. Med Oncol. 2015; 32:352.

46. Zheng Y, Cai Z, Wang S, Zhang X, Qian J, Hong S, Li H, Wang M, Yang J, Yi Q. Macrophages are an abundant component of myeloma microenvironment and protect myeloma cells from chemotherapy drug-induced apoptosis. Blood. 2009; 114:3625-3628.

47. Lin F, Luo J, Gao W, Wu J, Shao Z, Wang Z, Meng J, Ou Z, Yang G. COX-2 promotes breast cancer cell radioresistance via p38/MAPK-mediated cellular anti-apoptosis and invasiveness. Tumour Biol. 2013; 34:2817-2826.

48. Singh B, Cook KR, Vincent L, Hall CS, Berry JA, Multani AS, Lucci A. Cyclooxygenase-2 induces genomic instability, BCL2 expression, doxorubicin resistance, and altered cancer-initiating cell phenotype in MCF7 breast cancer cells. J Surg Res. 2008; 147:240-246.

49. Zatelli MC, Mole D, Tagliati F, Minoia M, Ambrosio MR, degli Uberti E. Cyclo-oxygenase 2 modulates chemoresistance in breast cancer cells involving NF-kappaB. Cell Oncol. 2009; 31:457-465.

50. Zatelli MC, Luchin A, Tagliati F, Leoni S, Piccin D, Bondanelli M, Rossi R, degli Uberti EC. Cyclooxygenase-2 inhibitors prevent the development of chemoresistance phenotype in a breast cancer cell line by inhibiting glycoprotein p-170 expression. Endocr Relat Cancer. 2007; 14:1029-1038.

51. Han Z, Hong L, Han Y, Wu K, Han S, Shen H, Li C, Yao L, Qiao T, Fan D. Phospho Akt mediates multidrug resistance of gastric cancer cells through regulation of P-gp, Bcl-2 and Bax. J Exp Clin Cancer Res. 2007; 26:261-268.

52. Mao Z, Zhou J, Luan J, Sheng W, Shen X, Dong X. Tamoxifen reduces $\mathrm{P}$-gp-mediated multidrug resistance via inhibiting the PI3K/Akt signaling pathway in ER-negative 
human gastric cancer cells. Biomed Pharmacother. 2014; 68:179-183.

53. Zhang B, Yin C, Li H, Shi L, Liu N, Sun Y, Lu S, Liu Y, Sun L, Li X, Chen W, Qi Y. Nir1 promotes invasion of breast cancer cells by binding to chemokine (C-C motif) ligand 18 through the PI3K/Akt/GSK3beta/Snail signalling pathway. Eur J Cancer. 2013; 49:3900-3913.

54. Leone V, di Palma A, Ricchi P, Acquaviva F, Giannouli M, Di Prisco AM, Iuliano F, Acquaviva AM. PGE2 inhibits apoptosis in human adenocarcinoma Caco-2 cell line through Ras-PI3K association and cAMP-dependent kinase A activation. Am J Physiol Gastrointest Liver Physiol. 2007; 293:G673-681.

55. Pan MR, Hou MF, Chang HC, Hung WC. Cyclooxygenase-2 up-regulates CCR7 via EP2/EP4 receptor signaling pathways to enhance lymphatic invasion of breast cancer cells. J Biol Chem. 2008; 283:11155-11163.

56. St-Germain ME, Gagnon V, Mathieu I, Parent S, Asselin E. Akt regulates COX-2 mRNA and protein expression in mutated-PTEN human endometrial cancer cells. Int J Oncol. 2004; 24:1311-1324.

57. Xia S, Zhao Y, Yu S, Zhang M. Activated PI3K/Akt/ COX-2 pathway induces resistance to radiation in human cervical cancer HeLa cells. Cancer Biother Radiopharm. 2010; 25:317-323

58. Wang SE, Xiang B, Guix M, Olivares MG, Parker J, Chung $\mathrm{CH}$, Pandiella A, Arteaga CL. Transforming growth factor beta engages TACE and ErbB3 to activate phosphatidylinositol-3 kinase/Akt in ErbB2-overexpressing breast cancer and desensitizes cells to trastuzumab. Mol Cell Biol. 2008; 28:5605-5620.

59. Sung WW, Lee H. The role of interleukin-10 in the progression of human papillomavirus-associated lung carcinoma. Oncoimmunology. 2013; 2:e25854.
60. Chen J, Yao Y, Gong C, Yu F, Su S, Liu B, Deng H, Wang F, Lin L, Yao H, Su F, Anderson KS, Liu Q, et al. CCL18 from tumor-associated macrophages promotes breast cancer metastasis via PITPNM3. Cancer Cell. 2011; 19:541-555.

61. Vosooghi M, Amini M. The discovery and development of cyclooxygenase-2 inhibitors as potential anticancer therapies. Expert Opin Drug Discov. 2014; 9:255-267.

62. Luo YP, Zhou H, Krueger J, Kaplan C, Liao D, Markowitz D, Liu C, Chen T, Chuang TH, Xiang R, Reisfeld RA. The role of proto-oncogene Fra-1 in remodeling the tumor microenvironment in support of breast tumor cell invasion and progression. Oncogene. 2010; 29:662-673.

63. Lacerda DI, Cysne-Finkelstein L, Nunes MP, De-Luca PM, Genestra Mda S, Leon LL, Berredo-Pinho M, MendoncaLima L, Matos DC, Medeiros MA, Mendonca SC. Kinetoplastid membrane protein-11 exacerbates infection with Leishmania amazonensis in murine macrophages. Mem Inst Oswaldo Cruz. 2012; 107:238-245.

64. Luo J, Deng ZL, Luo X, Tang N, Song WX, Chen J, Sharff KA, Luu HH, Haydon RC, Kinzler KW, Vogelstein B, He TC. A protocol for rapid generation of recombinant adenoviruses using the AdEasy system. Nat Protoc. 2007; 2:1236-1247.

65. Li H, Huang J, Yang B, Xiang T, Yin X, Peng W, Cheng W, Wan J, Luo F, Ren G. Mangiferin exerts antitumor activity in breast cancer cells by regulating matrix metalloproteinases, epithelial to mesenchymal transition, and betacatenin signaling pathway. Toxicol Appl Pharmacol. 2013; 272:180-190. 